\title{
The first international standard for human leptin and the first international standard for mouse leptin: comparison of candidate preparations by in vitro bioassays and immunoassays
}

\section{J Robinson, R Gaines Das, D Woollacott and participants in the study}

\author{
National Institute for Biological Standards and Control, South Mimms, Potters Bar, Hertfordshire \\ EN6 3QG, UK \\ (Requests for offprints should be addressed to C J Robinson, National Institute for Biological \\ Standards and Control, Blanche Lane, South Mimms, Potters Bar, Hertfordshire EN6 3QG, UK; \\ Email: jrobinson@nibsc.ac.uk)
}

\begin{abstract}
In an international collaborative study, two preparations of human sequence recombinant leptin and two preparations of mouse sequence recombinant leptin were evaluated, using in vitro bioassays and immunoassays, by eight laboratories, in three countries, for their suitability to serve as the international standard (IS) for human and mouse leptin respectively. The bioassays detected the human and mouse leptin with similar potency, while the immunoassays showed a greater response to the leptin of the species against which the antibody preparation had been raised. Comparison of the candidate standards with the various preparations of leptin of the same species currently assayed in the participating
\end{abstract}

laboratories showed that immunoassay measurements cannot be used to predict the biological potency. On the basis of the results reported here, in October 1999 the Expert Committee on Biological Standardization of the World Health Organization established the preparation coded $97 / 594$ as the first IS for human leptin, with an assigned unitage of $4000 \mathrm{IU} / a m p o u l e$, and the preparation coded $97 / 626$ as the first IS for mouse leptin, with an assigned unitage of $4000 \mathrm{IU} /$ ampoule. The ISs for leptin are distributed by the National Institute for Biological Standards and Control, UK, http:// www.nibsc.ac.uk.

Fournal of Molecular Endocrinology (2001) 27, 69-76

\section{INTRODUCTION}

Leptin, also referred to as Ob, was identified (Zhang et al. 1994) as the product of the $o b$ gene, a mutation which results in a morbid obesity in obese mice. It is synthesized as a 167-amino acid protein. Cleavage of the 21-amino acid signal sequence results in the 146-amino acid ( $\left.M_{\mathrm{r}} 16000\right)$ nonglycosylated leptin molecule found circulating in the plasma (Cohen et al. 1996). The leptin sequence is highly homologous across a range of mammalian species (Zhang et al. 1997), with human and mouse leptin sharing $84 \%$ amino acid sequence identity. Splice variants of the leptin receptor have been identified (for a review, see Friedman \& Halaas 1998), with only one form, $\mathrm{Ob}-\mathrm{Rb}$, having a cytoplasmic domain with all the protein motifs necessary to activate fully signal transduction.

Leptin plays a central role in regulating the balance of fuel stores and energy expenditure, is active in the immune (Lord et al. 1998) and reproductive (Chehab et al. 1997) systems, and has angiogenic activity (Sierra-Honigmann et al. 1998). The role of leptin in the control of body weight is the subject of intensive research, and leptin, and modified forms of the leptin molecule, have been investigated for the treatment of obesity. Valid interlaboratory comparison of potency and immunoassay measurements of leptin samples requires the use of a common reference standard. The National Institute for Biological Standards and Control (NIBSC) therefore obtained and ampouled preparations of human and mouse leptin, the two 
TABLE 1. Bioassays

\section{Cell type}

\begin{tabular}{llll} 
Parameter measured & $\begin{array}{l}\text { Lab. } \\
\text { code }\end{array}$ & $\begin{array}{l}\text { Assay } \\
\text { code* }\end{array}$ \\
\cline { 1 - 2 } AlamarBlue reduction by absorbance & 5 & & B5 \\
AlamarBlue reduction by fluorescence & 8 & & B $8 \mathrm{~h}$ \\
Luciferase activity & 2 & & B2h \\
& 2 & & B2m
\end{tabular}

32D-expressing chimeric receptor with Ob-R extracellular domain
HEK-293-expressing Ob-Rb and luciferase under STAT-inducible promoter

\begin{abstract}
Activated STAT-induced transcription

Assay type

Cell metabolic activity
\end{abstract}

* $\mathrm{B}=$ bioassay; number $=\mathrm{lab}$. code; $\mathrm{h}=$ human and $\mathrm{m}=$ mouse for IHS and form of leptin the assay is designed to measure. most frequently measured species, and organized their evaluation by international collaborative study for their suitability to serve as the international standard for the respective species.

\section{Aims of the study}

The aims were to establish an international standard (IS) and the international unitage for human leptin and for mouse leptin by: (i) assessing the suitability of each of the candidate preparations of human and mouse leptin to serve as a standard in bioassays and immunoassays; (ii) comparing the candidate preparations with each other and with local standards; (iii) assessing the stability of each of the candidates by comparing them with ampoules of the same preparation subjected to accelerated thermal degradation; and (iv) estimating the nominal mass content of the ampoules for the purposes of calibrating immunoassays

\section{Participants in the study}

The following participants, listed alphabetically by country, contributed data to the study. In this report, each laboratory is identified by a number from 1 to 8 that is not related to this order of listing. Dr M W Elmlinger and Prof. Dr M B Ranke, Pediatric Endocrinology, Children's Hospital, Hoppe-Seyler-Str. 1, D-72076 Tuebingen, Germany; Dr A Janetzko, DRG Instruments GmbH, Frauenbergstr. 18, D-35039 Marburg, Germany; Dr J Kratzsch and Prof. Dr W Kiess, University of Leipzig, Department of Clinical Chemistry, Liebigstr. 27a, 04103 Leipzig, Germany and Department of Pediatrics, Oststr. 21-25, 04317 Leipzig, Germany, respectively; Dr L Pridzun, Mrs S Perrucci and Mr K-H Lindau, Mediagnost GmbH, Aspenhaustr. 25, D-72770 Reutlingen, Germany; Mr B Rafferty, Mr R Stammers and Ms J Wickenden, NIBSC, Blanche Lane, South Mimms, Potters Bar, Herts EN6 3QG, UK; Prof. P
Trayhurn and Miss $\mathrm{J} \mathrm{T}$ Crabtree, Division of Biomedical Science, Rowett Research Institute, Bucksburn, Aberdeen AB21 9SB, UK; Ms S Andrade and Ms J Schwanauer, Amgen Inc., One Amgen Center Drive, Thousand Oaks, CA 913201789, USA; and Dr C I Rosenblum and Ms A Vongs, Merck Research Laboratories, PO Box 2000, RY80 M-213, Rahway, NJ 07065, USA.

\section{MATERIALS AND METHODS}

Two preparations of human sequence recombinant (rh) leptin and three preparations of mouse sequence recombinant $(\mathrm{rm})$ leptin were donated to the World Health Organization (WHO) (see Acknowledgements). Potential excipients were tested for interference in an in vitro bioassay (Table 1 , assay code B5) and two immunoassays (Table 2, assay codes $\mathrm{E} 5 \mathrm{~h}$ and $\mathrm{E} 5 \mathrm{~m})$. Trial fills were conducted and the lyophilized leptin was compared with the bulk material and tested for its stability on storage at elevated temperatures. Two preparations each of rh and rm leptin, all synthesized in E. coli, were then ampouled at NIBSC, following Expert Committee on Biological Standardization (ECBS) guidelines (WHO 1990), and were coded as detailed in Table 3.

Buffer, final composition sodium citrate $(10 \mathrm{mM}$ $\mathrm{pH} 5 \cdot 2$ ), $2 \mathrm{mg} / \mathrm{ml}$ trehalose (Fluka Chemie AG, Buchs, Switzerland) and $5 \mathrm{mg} / \mathrm{ml}$ human serum albumin (Baxter Healthcare Corporation, Glendale, CA, USA), was prepared using nonpyrogenic water (Baxter Healthcare) and depyrogenated glassware. Before addition of the albumin, the solution was passed through a $0.22 \mu \mathrm{m}$ APD membrane filter (Sartorius, Surrey, UK).

The concentrations of the leptin preparations received as frozen solutions were determined by the manufacturers by measuring the absorbance at $280 \mathrm{~nm}$. On thawing, the solutions were clear, and were used without filtering. Approximately $10 \mathrm{mg}$ 
TABLE 2. Immunoassays

\section{First antibody/binding}

$\begin{array}{ll}\text { Assay type } & \\ \text { IFA } & \begin{array}{l}\text { Solid phase rhOb-R extracellular } \\ \text { domain, then anti-rh leptin } \\ \text { (rabbit IgG) }\end{array} \\ \text { ELISA } & \text { Anti-rh leptin (rabbit) }\end{array}$

Anti-rh leptin (mouse monoclonal)

Anti-rm leptin (rat monoclonal)

Anti-rh leptin (rabbit IgG)

Anti-rm leptin (rabbit IgG)

RIA

Anti-rh leptin (rabbit $\mathrm{IgG}$ )
Anti-rh leptin (rabbit Ig)

Anti-rh leptin (rabbit Ig)

Anti-rh leptin (rabbit Ig)

Anti-rm leptin (rabbit Ig)

Anti-rh leptin (rabbit antiserum)

\section{Second antibody/detection}

Anti-rabbit IgG (goat)

Anti-rh leptin (mouse monoclonal)

Anti-rh leptin (mouse monoclonal) biotinylated

Anti-rm leptin (goat polyclonal) biotinylated

Anti-rh leptin (rabbit IgG)

Anti-rm leptin (rabbit IgG)

Anti-rabbit IgG (goat)

Anti-rabbit IgG

Anti-rabbit IgG

Anti-rabbit IgG

Anti-rabbit IgG
Lab. Assay

code code* Reference

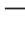

1

F1h

Kratzsch et al. (1999)

$4 \quad$ E4h

DRG Instruments GmbH, Germany, DRG EIA-2395 (leptin, sandwich)

5 E5h In-house, unpublished

$5 \quad$ E5m In-house, unpublished

6 E6h Hardie et al. (1997)

$6 \quad$ E6m Hardie et al. (1996)

$1 \quad$ R1h Kratzsch et al. (1999)

3 R3hs Mediagnost GmbH, Germany, Human-Leptin-Sensitive-RIA, LEP-R40/41

3 R3h Mediagnost, Human-LeptinStandard-RIA, LEP-R42/43

$7 \quad$ R7hs Mediagnost, Human-LeptinSensitive-RIA, LEP-R40/41

3 R3m Mediagnost, Mouse/RatLeptin-RIA, LEP-R61

$4 \quad \mathrm{C} 4 \mathrm{~h}$
DRG Instruments, DRG EIA-1863 (leptin, competitive)

*The first character denotes the assay type ( $\mathrm{C}=$ competitive EIA, E=ELISA ( denotes the lab. code; the third character denotes the IHS, human (h) or mouse (m) (all recombinant), and the form of leptin, human or mouse, this assay is designed to measure and $\mathrm{s}$ denotes a high sensitivity version of an immunoassay.

TABLE 3. Leptin candidate standards

\begin{tabular}{|c|c|c|c|c|c|c|}
\hline & $\begin{array}{l}\text { Leptin } \\
\text { type }\end{array}$ & Form received & $\begin{array}{l}\text { Mean fill } \\
\text { weight }(g)\end{array}$ & $\begin{array}{l}\text { Weight } \\
\text { range }(\mathrm{g})\end{array}$ & $\begin{array}{l}\text { Residual } \\
\text { moisture }(\%)\end{array}$ & $\begin{array}{l}\text { Predicted } \\
\text { leptin per } \\
\text { ampoule }(\mu \mathrm{g})\end{array}$ \\
\hline \multicolumn{7}{|c|}{ Ampoule code } \\
\hline $97 / 630$ & Human & Solution $(2.6 \mathrm{mg} / \mathrm{ml})$ & $1 \cdot 0046$ & $1 \cdot 0005-1 \cdot 0088$ & $0 \cdot 376$ & $3 \cdot 8$ \\
\hline $97 / 626$ & Mouse & Solution $(6.65 \mathrm{mg} / \mathrm{ml})$ & $1 \cdot 0059$ & $1 \cdot 0027-1 \cdot 0106$ & $0 \cdot 360$ & $4 \cdot 0$ \\
\hline $98 / 558$ & Mouse & Lyophilized & $1 \cdot 0079$ & $1 \cdot 0064-1 \cdot 0092$ & $0 \cdot 199$ & 4 \\
\hline
\end{tabular}

of the preparation received as a lyophilized powder were dissolved in $3 \mathrm{ml} \mathrm{PBS}$ and filtered through a $0 \cdot 2 \mu \mathrm{m}$ low protein-binding sterile Acrodisc 13 (Gelman Sciences, Ann Arbor, MI, USA). The concentration of the solution was measured by absorbance and by Bio-Rad protein assay (Bio-Rad, Hemel Hempsted, Herts, UK) using BSA standard. For each preparation, the appropriate volume was

www.endocrinology.org added to the citrate buffer to give $3 \cdot 6 \pm 1 \%$ liters of a solution of concentration around $4 \mu \mathrm{g} / \mathrm{ml}$ leptin, and this solution was distributed in $1 \mathrm{ml}$ aliquots, giving the theoretical leptin content per ampoule shown in Table 3.

The leptin content of the ampoules cannot be verified by direct measurement of absolute mass, so the content is assumed to be the theoretical mass, 
calculated from the dilution of the bulk material of known leptin mass content. This value is described in units of 'predicted $\mu \mathrm{g}$ '. The leptin content of each batch of serum albumin was below the level of detection of the in-house immunoassay and could thus contribute a maximum of 2 parts per million of the total leptin content of an ampoule.

For each fill, 60-70 ampoules were weighed. The mean fill weights are shown in Table 3. Each solution was lyophilized, and the ampoules were sealed under dry nitrogen by heat fusion of the glass and stored at $-20{ }^{\circ} \mathrm{C}$ in the dark. Residual moisture of each preparation (mean of three ampoules), measured by the Karl-Fischer method, ranged from $0 \cdot 20$ to $0 \cdot 38 \%$.

The ampouled preparations were subjected to preliminary in-house testing to verify recovery of immunological reactivity and biological activity on lyophilization. Reconstituted ampoules were also subjected to cycles of freeze-thawing to verify that these preparations could be aliquoted on reconstitution, and frozen aliquots stored for later use.

\section{Design of the study}

Each participant received a selection of coded ampoules of the candidate standards and degradation samples, and labeled ampoules of lyophilized excipient. The degradation samples had been stored at $4{ }^{\circ} \mathrm{C}, 20{ }^{\circ} \mathrm{C}, 37^{\circ} \mathrm{C}$ and $45^{\circ} \mathrm{C}$ for periods of $3-13$ months. Participants were asked to assay specified sets of ampoules, following their normal in vitro bioassay and immunoassay protocols, with two independent assays (each using freshly reconstituted ampoules) by each method, and to include their in-house standard (IHS), measuring responses at several dose levels with replicates for each sample. Pairs of samples, identical apart from their code (coded duplicates), were included to provide a direct measure of the intra-assay variation. To permit suitable dilution series to be made, participants were asked to assume a leptin content of $4 \mu \mathrm{g} /$ ampoule. To test for any effect of the lyophilization excipient, some participants were asked to assay their IHS in the presence of excipient, with the leptin:excipient ratio similar to that of the candidate standards. To test for the specificity of assays for human or mouse leptin, ampoules of both forms were included in some sets.

\section{Bioassays and immunoassays}

The test samples were examined in a variety of in vitro bioassays and immunoassays, as detailed in
Tables 1 and 2. The bioassays were based on the responses of two different genetically modified cell lines. One line (assay codes B5 and B8h) was a 32D transfectant expressing a chimeric receptor comprising the extracellular ligand-binding domain of the human leptin receptor, Ob-R, and the transmembrane and intracellular domains of the murine erythropoietin receptor (Crouse et al. 1998). The second line (assay codes $\mathrm{B} 2 \mathrm{~h}$ and $\mathrm{B} 2 \mathrm{~m}$ ) was an HEK-293 transfectant expressing the signal-transducing form of the leptin receptor, $\mathrm{Ob}-\mathrm{Rb}$, and a STAT-inducible promoter regulating firefly luciferase cDNA (Rosenblum et al. 1998).

One laboratory used an immunofunctional assay (IFA) (assay code F1h) in which leptin was captured by immobilized recombinant extracellular, ligand-binding, domain of the human leptin receptor and the bound leptin was identified by rabbit IgG raised against rh leptin (Kratzsch et al. 1999).

Both commercial and in-house immunoassays were used for human and mouse leptin. Brief details and references are given in Table 2.

\section{Statistical analysis}

Data for each assay were examined both graphically and using analysis of variance (Gaines Das \& Rice 1985), and outliers were omitted before further analysis. The majority of dose-response curves could be described using a four parameter logistic model. For these, asymptotes were determined and analysis of transformed responses was carried out using an in-house program, WRANL (Gaines Das \& Tydeman 1982), which provides weighted regression analysis of logit response on $\log$ dose with an assessment of linearity and parallelism, and estimates of relative potency. One laboratory (code 6) assayed test samples at a single dose and potencies for these were determined assuming all preparations would have given dose-response lines parallel to the IHS.

For calculation of the relative potencies, the theoretical ampoule contents were corrected from the $4 \mu \mathrm{g}$ leptin/ampoule assumed by the participants to the predicted values detailed in Table 3 . Estimates of relative potency were combined as geometric means and confidence limits were determined using variance of the log potency estimates. The geometric coefficient of variation (GCV, determined as $\exp (\mathrm{s})-1$, multiplied by 100 to give percent, where $s$ is the standard deviation of the log potency estimates) has been used to provide a measure of the precision of estimates. 
TABLE 4. Potency of candidate standards: laboratory and method geometric mean estimates for human leptin, 97/594 and $97 / 630$, and mouse leptin, $97 / 626$ and $98 / 558$, relative to the various IHSs, expressed as $\mu \mathrm{g}$ IHS per predicted $\mu \mathrm{g}$ ampouled preparation, and of $97 / 630$ relative to $97 / 594,97 / 626$ relative to $97 / 594,98 / 558$ relative to $97 / 594$ and of $98 / 558$ relative to $97 / 626$. Estimates are based on direct within-assay comparisons

\begin{tabular}{|c|c|c|c|c|c|c|c|c|}
\hline & $\begin{array}{l}\mathbf{9 7 / 5 9 4} \\
\text { (human) }\end{array}$ & $\begin{array}{l}\mathbf{9 7 / 6 3 0} \\
\text { (human) }\end{array}$ & $\begin{array}{l}\mathbf{9 7 / 6 2 6} \\
\text { (mouse) }\end{array}$ & $\begin{array}{l}\mathbf{9 8 / 5 5 8} \\
\text { (mouse) }\end{array}$ & 97/630:97/594 & 97/626:97/594 & 98/558:97/594 & $98 / 558: 97 / 626$ \\
\hline \multicolumn{9}{|l|}{ Assay code* } \\
\hline $\mathrm{B} 2 \mathrm{~h}$ & $0 \cdot 76$ & $0 \cdot 68$ & - & - & $0 \cdot 85$ & - & - & - \\
\hline $\mathrm{B} 2 \mathrm{~m}$ & 0.79 & - & $0 \cdot 86$ & $0 \cdot 84$ & - & $1 \cdot 05$ & - & $0 \cdot 93$ \\
\hline B5 & No IHS & - & - & - & $0 \cdot 41$ & $1 \cdot 44$ & $1 \cdot 05$ & $0 \cdot 73$ \\
\hline $\mathrm{B} 8 \mathrm{~h}$ & $0 \cdot 64$ & $0 \cdot 42$ & $0 \cdot 78$ & 0.59 & $0 \cdot 66$ & $1 \cdot 11$ & $0 \cdot 81$ & $0 \cdot 76$ \\
\hline $\mathrm{E} 4 \mathrm{~h}$ & $1 \cdot 06$ & $0 \cdot 65$ & - & - & $0 \cdot 61$ & - & - & - \\
\hline $\mathrm{E} 5 \mathrm{~h}$ & No IHS & - & - & - & $0 \cdot 42$ & $0 \cdot 18$ & - & - \\
\hline $\mathrm{E} 5 \mathrm{~m}$ & No IHS & - & - & - & - & $9 \cdot 78$ & $5 \cdot 68$ & $0 \cdot 58$ \\
\hline E6h & 0.95 & $1 \cdot 14$ & - & - & $1 \cdot 20$ & - & - & - \\
\hline E6m & - & - & $0 \cdot 96$ & $0 \cdot 57$ & - & - & - & $0 \cdot 60$ \\
\hline R1h & $1 \cdot 01$ & $0 \cdot 79$ & - & - & $0 \cdot 78$ & - & - & - \\
\hline $\mathrm{R} 3 \mathrm{~h}$ & $1 \cdot 06$ & $0 \cdot 74$ & - & - & $0 \cdot 70$ & - & - & - \\
\hline R3hs & $1 \cdot 07$ & $0 \cdot 74$ & - & - & $0 \cdot 69$ & - & - & - \\
\hline $\mathrm{R} 3 \mathrm{~m}$ & - & - & $1 \cdot 43$ & $0 \cdot 95$ & - & - & - & $0 \cdot 67$ \\
\hline R7hs & $1 \cdot 15$ & $0 \cdot 81$ & $0 \cdot 20$ & $0 \cdot 30$ & $0 \cdot 70$ & $0 \cdot 18$ & $0 \cdot 26$ & $1 \cdot 46$ \\
\hline $\mathrm{C} 4 \mathrm{~h}$ & 1.09 & $0 \cdot 80$ & - & - & $0 \cdot 74$ & - & - & - \\
\hline F1h & $1 \cdot 35$ & 0.76 & - & - & 0.56 & - & - & - \\
\hline
\end{tabular}

*Detailed in Tables 1 and 2.

\section{RESULTS}

The test samples were examined in in vitro bioassays, immunoassays and a ligand IFA (a total of 57 assays), as detailed in Tables 1 and 2. The leptin candidate standards and IHS of the same species behaved similarly to each other; the dose-response lines were generally found to be linear and parallel. Fewer than $0 \cdot 1 \%$ of the responses were deleted as outliers. In the assay R7hs for human leptin, the two mouse leptin candidate standards gave responses near the end of the range, so a single dose was used to calculate approximate potencies, and the data were not used for any other calculations.

\section{Assay accuracy and precision assessed using coded duplicates}

Under ideal conditions, coded duplicate preparations would have identical activities, and the deviation of the relative potency from the value of 1 reflects both the accuracy and precision of the assay. Comparison of the first of each pair of coded duplicates with the second gave values close to the expected relative potency of 1 ; the overall geometric mean of assay means for each pair was $1.05(95 \%$ limits: 0.99-1.09).

Within assays, the deviation of the relative potency of the duplicates from the value 1 shows the $95 \%$ limits for an individual potency estimate would be 70-143\% (GCV 20\%). Between assays, within a laboratory, the variability was similar (GCV 18\%). This is typical of the precision seen for many in vitro assays (Robinson et al. 1998, Gaines Das et al. 1999).

\section{Comparison of the candidate standards with each other and with the IHSs}

Estimates of the relative potency of the candidate standards in terms of the various IHSs are summarized in Table 4.

Estimates by immunoassays of the human leptin per ampoule in terms of the various human leptin IHSs are consistent with the predicted value of $5 \mu \mathrm{g}$ for $97 / 594$ and $4 \mu \mathrm{g}$ for $97 / 630$. Similarly, the estimates by immunoassays of the mouse leptin per ampoule in terms of mouse leptin IHSs are consistent with the predicted value of $4 \mu \mathrm{g}$ for $97 / 626$ and $4 \mu \mathrm{g}$ for 98/558. Both human and mouse immunoassays give higher measurements for leptin of the appropriate species than of the other species.

Comparison of the candidate standards and the IHSs of the same species shows that the ratio of biological to immunological activity varies between preparations. Preparation 97/594, for example, shows a lower ratio of biological to immunological activity than do the various human IHSs, as illustrated by the distribution of potency estimates by the different assay systems, shown in Fig. 1. 


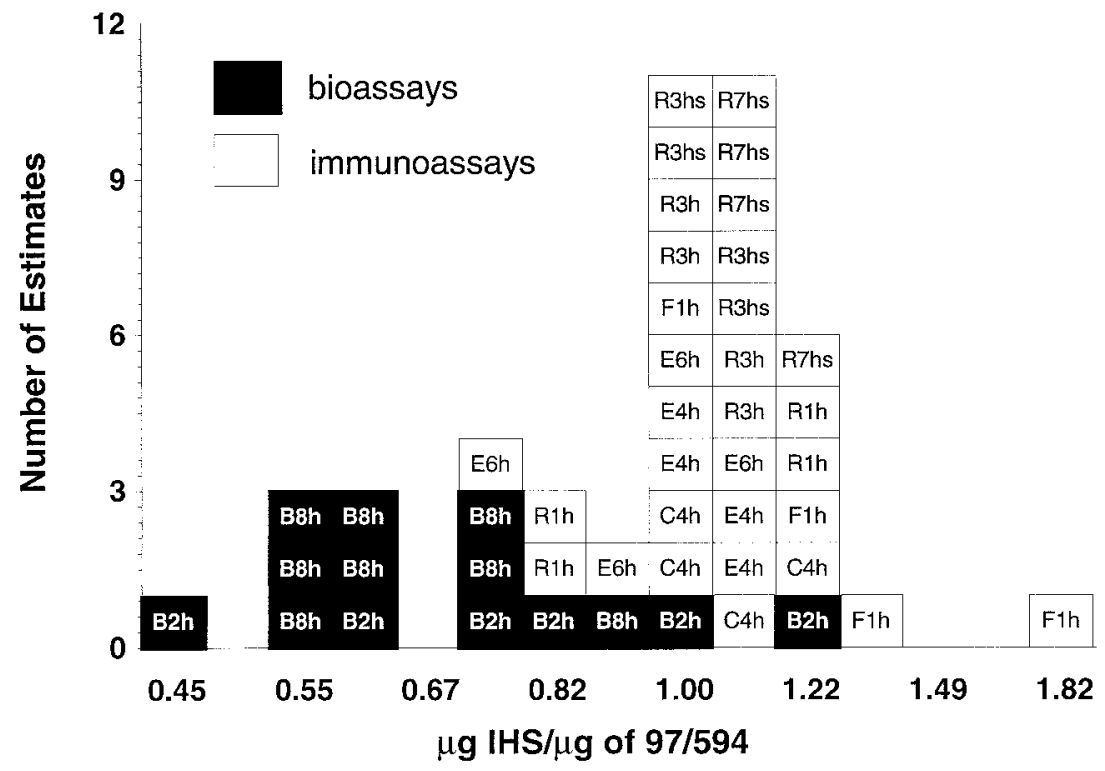

FIGURE 1. Potency of preparation 97/594, first IS for leptin, relative to the various human leptin IHSs, expressed as $\mu$ g IHS per predicted $\mu$ g of $97 / 594$. Each square represents an independent assay and the designation in the square is the assay code as shown in Tables 1 and 2 . The distribution of estimates shows that $97 / 594$ has a higher ratio of immunological to biological activity than do the various IHSs.

Comparisons of the two human leptin candidate standards with each other and of the two ampouled mouse leptin preparations with each other gave estimates which were broadly consistent between laboratories. The overall geometric means of laboratory mean estimates were 0.68 predicted $\mu \mathrm{g}$ of $97 / 594$ equivalent to 1 predicted $\mu \mathrm{g}$ of $97 / 630$ (GCV $35 \%$ ) and 0.77 predicted $\mu$ g of $96 / 626$ equivalent to 1 predicted $\mu \mathrm{g}$ of $98 / 558$ (GCV 39\%). In contrast, the between-laboratory variability for comparison of either human preparation with either mouse preparation was substantially larger with, in each case, GCV greater than $200 \%$.

Bioassay comparison of mouse and human leptins was limited to two or three laboratories. Estimates for comparison of either mouse leptin with human leptin 97/594 (mean relative potencies 1.05, 1.42, $1 \cdot 11$ for $97 / 626$ and $1 \cdot 04,0 \cdot 84$ for $98 / 558$ ) showed better agreement than estimates for comparison of either mouse leptin with human leptin 97/630 (relative potencies $3 \cdot 51,1.72$ for $97 / 626$ and $2 \cdot 57$, $1 \cdot 25$ for $98 / 558)$.

\section{Effect of the lyophilization excipient}

The activity of the participants' IHS preparations of leptin, assayed in the normal manner, was compared with the activity of the IHS assayed in the presence of the excipient used in the preparation of the candidate standards (at a leptin:excipient ratio similar to that in the candidate standards). The excipient did not appear to have any effect; the geometric mean of the ratio of activity of the IHS to activity in the presence of excipient was $1.01(95 \%$ limits: $0 \cdot 95-1 \cdot 07)$.

\section{Stability}

Stability of the candidate standards was assessed using thermally degraded samples. For each preparation there was a tendency for samples which had been stored at $+45^{\circ} \mathrm{C}$ to have slightly lower potencies than the samples stored continuously at $-20{ }^{\circ} \mathrm{C}$, but these differences were not significant compared with the assay variability as assessed by the coded duplicates. Samples stored at lower temperatures showed no evidence of decreased potency, as shown in Table 5 .

\section{DISCUSSION}

For the preparations of human leptin, as for the preparations of mouse leptin, the dose-response 
TABLE 5. Stability of candidate standards. Geometric mean of all individual estimates, with 95\% confidence intervals, for thermally accelerated degradation samples, calculated ignoring differences in assay methods and in storage times for some samples. The minimum time of storage at any of the elevated temperatures has been given, although in several cases samples were stored at some temperatures for longer times

\begin{tabular}{|c|c|c|c|c|c|c|}
\hline & \multirow{2}{*}{$\begin{array}{l}\text { Minimum } \\
\text { storage } \\
\text { (days) }\end{array}$} & \multicolumn{5}{|c|}{ Storage temperature $\left({ }^{\circ} \mathrm{C}\right)$} \\
\hline & & -20 & 4 & 20 & 37 & 45 \\
\hline \multicolumn{7}{|l|}{ Leptin } \\
\hline $97 / 594$ & 349 & $1 \cdot 00(0 \cdot 90-1 \cdot 11)$ & $1 \cdot 04(0 \cdot 94-1 \cdot 16)$ & $1 \cdot 10(0 \cdot 98-1 \cdot 24)$ & $0.94(0 \cdot 85-1.05)$ & $0.92(0.83-1 \cdot 02)$ \\
\hline $97 / 630$ & 168 & $1 \cdot 01(0 \cdot 95-1 \cdot 08)$ & $1 \cdot 00(0 \cdot 95-1 \cdot 05)$ & $0.98(0.90-1.07)$ & $0.90(0 \cdot 82-1 \cdot 00)$ & $0.84(0.69-1.02)$ \\
\hline $97 / 626$ & 294 & $1 \cdot 05(0 \cdot 91-1 \cdot 22)$ & $1 \cdot 07(0 \cdot 89-1 \cdot 29)$ & $1 \cdot 06(0 \cdot 84-1 \cdot 33)$ & $1 \cdot 05(0 \cdot 89-1 \cdot 22)$ & $0.98(0.55-1.72)$ \\
\hline $98 / 558$ & 92 & $1.03(0.99-1.07)$ & $1 \cdot 04(0 \cdot 97-1 \cdot 10)$ & $0 \cdot 90(0 \cdot 68-1 \cdot 19)$ & $1 \cdot 05(0 \cdot 95-1 \cdot 15)$ & $0.91(0 \cdot 81-1 \cdot 01)$ \\
\hline
\end{tabular}

curves of the two candidate standards and the various IHSs are parallel, so valid comparisons of potency can be made between the various human preparations and between the various mouse preparations. Interlaboratory variation in estimates of leptin potency is reduced by use of a common standard in place of various IHSs.

The bioassays detect the human and mouse leptin with similar potency. The bioassays are all based on cell lines which express either the long form of the human leptin receptor or the extracellular domain of the human leptin receptor in a chimeric molecule. This cross-species activity is similar to the situation in vivo where human leptin is biologically active in mice (Verploegen et al. 1997). In contrast, the immunoassays in which both human and mouse leptin were tested showed a much greater response to the leptin species against which the antibody preparation had been raised.

Comparison of the two human leptin candidate standards with each other and with the various IHSs, in assays designed to measure human leptin, gave generally consistent relative potencies across the bioassays and across the immunoassays, with $97 / 630$ generally less potent than $97 / 594$. However, there is a difference between the bioassay and immunoassay results, with both candidates showing a lower biological to immunological potency ratio than the IHSs. Similar comparison of the mouse leptin preparations in assays designed for mouse leptin, shows consistent relative potencies across the bioassays and across the immunoassays, but comparison of bioassay and immunoassay data shows that $97 / 626$ is relatively more biologically active than 97/558. These results illustrate the general principle that immunoassay measurements cannot be used to predict biological potency.

The excipient in which the four candidate standards were lyophilized had no detected effect on any of the assay systems in which it was tested, so each of the candidates could be used as a standard without any requirement to compensate for interference from the excipient.

All of the candidate standards were judged, from the accelerated thermal degradation results, to be sufficiently stable to serve as a standard. Although there was a tendency for samples which had been stored at $+45^{\circ} \mathrm{C}$ to show a small decrease in activity compared with the samples stored continuously at $-20{ }^{\circ} \mathrm{C}$, this difference was not judged significant when compared with the variation in estimates for the coded duplicates. Samples stored at lower temperatures showed no decrease in potency.

On the basis of the consistency of the estimates of potency and predicted stability on storage, both of the human leptin candidates and both of the mouse leptin candidates are suitable to serve as standards for the relevant form of leptin. For both human and mouse leptin, it was proposed that the candidate for which there is longer-term degradation data and which shows the higher potency be selected as the first IS.

With the agreement of the participants in the collaborative study, at its 50th meeting in Geneva, in 1999, the ECBS of WHO established preparation $97 / 594$ as the first IS for human leptin, with an assigned unitage of $4000 \mathrm{IU} /$ ampoule and preparation $97 / 626$ as the first IS for mouse leptin, with an assigned unitage of $4000 \mathrm{IU} /$ ampoule, with the statements that for the purpose of immunoassay calibration, the nominal human leptin content of $97 / 594$ may be assumed to be $5 \mu \mathrm{g}$ /ampoule and the nominal mouse leptin content of 97/626 may be assumed to be $4 \mu \mathrm{g} / \mathrm{ampoule}$, and that these data should not be assumed to validate the use of immunoassay for the control of potency of therapeutic preparations of leptin. The IS may be obtained for use in the calibration of local standards by writing to NIBSC, PO Box 1193, Potters Bar, EN6 3QH, UK, or through Web site http:// www.nibsc.ac.uk. 


\section{ACKNOWLEDGEMENTS}

Grateful acknowledgements are due to Amgen, Inc., Novartis Pharma AG, R\&D Systems, Inc., and SmithKline Beecham Pharmaceuticals for donations of preparations of leptin and reagents for assay systems, and expert technical advice, to the participants in the collaborative study, and to the participants at the European Leptin Symposium in Giessen 1997, who provided helpful advice.

\section{REFERENCES}

Chehab FF, Mounzih K, Lu R \& Lim ME 1997 Early onset of reproductive function in normal female mice treated with leptin. Science 275 88-90.

Cohen SL, Halaas JL, Friedman, Chait BT, Bennett L, Chang D, Hecht R \& Collins F 1996 Human leptin characterization. Nature 382589.

Crouse JA, Elliott GE, Burgess TL, Chiu L, Bennett L, Moore J, Nicolson M \& Pacifici RE 1998 Altered cell surface expression and signaling of leptin receptors containing the fatty mutation. Fournal of Biological Chemistry 273 18365-18373.

Friedman JM \& Halaas JL 1998 Leptin and the regulation of body weight in mammals. Nature $395763-770$.

Gaines Das RE \& Tydeman MS 1982 Iterative weighted regression analysis of logit responses: a computer program analysis of bioassays and immunoassay data. Computer Programs in Biomedicine 15 13-22.

Gaines Das RE \& Rice LR 1985 SCAN, an exploratory program for preliminary analysis of bioassay and immunoassay data. Computer Programs in Biomedicine 21 25-33.

Gaines Das RE, Heath AB, Martin H \& Sesardic D 1999 Validation of in vitro assays for botulinum toxin: a case study. Developments in Biological Standardization 101 267-276.

Hardie LJ, Rayner DV, Holmes S \& Trayhurn P 1996 Circulating leptin levels are modulated by fasting, cold exposure and insulin administration in lean but not Zucker $(\mathrm{fa} / \mathrm{fa}$ ) rats as measured by ELISA. Biochemical and Biophysical Research Communications 223 660-665.

Hardie L, Trayhurn P, Abramovich D \& Fowler P 1997 Circulating leptin in women: a longitudinal study in the menstrual cycle and during pregnancy. Clinical Endocrinology 47 101-106.

Kratzsch J, Berthold A, Kiess W \& Keller E 1999 A rapid, quantitative immunofunctional assay (IFA) for measuring human leptin. Hormone Research 51 (Suppl 2) 123.

Lord GM, Matarese G, Howard JK, Baker RJ, Bloom SR \& Lechler RI 1998 Leptin modulates the T-cell immune response and reverses starvation induced immunosuppression. Nature 394 897-891.

Robinson CJ, Stammers R \& Gaines Das R 1998 The international standard for platelet-derived growth factor-BB: comparison of candidate preparations by in vitro bioassays and immunoassays. Growth Factors 16 153-160.

Rosenblum CI, Vongs A, Tota MR, Varnerin JP, Frazier E, Cully DF, Morsy MA \& Van der Ploeg LHT 1998 A rapid, quantitative functional assay for measuring leptin. Molecular and Cellular Endocrinology 143 117-123.

Sierra-Honigmann MR, Nath AK, Murakami C, GarciaCardena G, Papapetropoulos A, Sessa WC, Madge LA, Schechner JS, Schwabb MB, Polverini PJ \& Flores-Riveros JR 1998 Biological action of leptin as an angiogenic factor. Science 281 1683-1686.

Verploegen SABW, Plaetinck G, Devos R, Van der Heyden J \& Guisez Y 1997 A human leptin mutant induces weight gain in normal mice. FEBS Letters 405 237-240.

WHO 1990 Technical Report Series 800, Annex 4. WHO, Geneva, Switzerland.

Zhang F, Basinski MB, Beals JM, Briggs SL, Churgay LM, Clawson DK, Di Marchi RD, Furman TC, Hale JE, Hsiung HM, Schoner BE, Smith DP, Zhang XY, Wery JP \& Schevitz RW 1997 Crystal structure of the obese protein leptin-E100. Nature 387 206-209.

Zhang Y, Proenca R, Maffei M, Barone M, Leopold L \& Friedman JM 1994 Positional cloning of the mouse obese gene and its human homologue. Nature 372 425-432.

RECEIVED IN FINAL FORM 1 March 2001

ACCEPTED 7 March 2001 